\title{
Effect of the surface area of cobaltic oxide on carbon monoxide oxidation
}

\author{
Chen-Bin Wang ${ }^{\mathrm{a}, *}$, Chih-Wei Tang ${ }^{\mathrm{a}, \mathrm{b}}$, Shiue-Jiun Gau ${ }^{\mathrm{a}, \mathrm{b}}$, and Shu-Hua Chien ${ }^{\mathrm{b}, \mathrm{c}, *}$ \\ ${ }^{a}$ Department of Applied Chemistry, Chung Cheng Institute of Technology, National Defense University, Tahsi, Taoyuan, 33509 Taiwan, \\ Republic of China \\ ${ }^{b}$ Institute of Chemistry, Academia Sinica, Taipei, 11529 Taiwan, Republic of China \\ ${ }^{c}$ Department of Chemistry, National Taiwan University, Taipei, 10764 Taiwan, Republic of China
}

Received 24 November 2004; accepted 3 December 2004

\begin{abstract}
Various surface area $\left(S_{\mathrm{BET}}\right)$ of cobaltic oxide $\left(\mathrm{Co}_{3} \mathrm{O}_{4}\right)$ are prepared by different methods, i.e., precipitation-oxidation, impregnation and hydrothermal. The effect of $S_{\mathrm{BET}}$ of $\mathrm{Co}_{3} \mathrm{O}_{4}$ on the catalytic property toward $\mathrm{CO}$ oxidation is investigated. The results indicate that the optimum $S_{\mathrm{BET}}$ of $\mathrm{Co}_{3} \mathrm{O}_{4}$ could increase the catalytic activity. Characterization of the cobaltic oxide using X-ray diffraction (XRD), $\mathrm{N}_{2}$-adsorption at $-196{ }^{\circ} \mathrm{C}$, infrared (IR) and temperature-programmed reduction (TPR) reveals that the increase of $S_{\mathrm{BET}}$ on $\mathrm{Co}_{3} \mathrm{O}_{4}$ can weaken the bond strength of $\mathrm{Co}-\mathrm{O}$ and promote more lattice oxygen desorption from $\mathrm{Co}_{3} \mathrm{O}_{4}$ to cause the reduction become easy. We conclude that the $S_{\mathrm{BET}}$ effect, caused by various prepared methods and refined conditions, are responsible for the activity enhancement of $\mathrm{Co}_{3} \mathrm{O}_{4}$. The $T_{50}$ (the conversion of $\mathrm{CO}$ reached $50 \%$ ) is decreased significantly when the $S_{\text {BET }}$ is increased, i.e., PO-R230 $>$ PO-C400 $>$ I-C550 $>$ H-150 $\sim$ D-Strem.
\end{abstract}

KEY WORDS: cobaltic oxide; surface area; $\mathrm{CO}$ oxidation.

\section{Introduction}

The complete oxidation of carbon monoxide is of prime importance in environmental pollution control. Precious metals are well know catalysts with high activity and widely used for exhaust gas emission control [1-3]. However, the high cost of precious metals and their sensitivity to sulfur poisoning have long motivated the search for substitute catalysts. Considerable attention has been paid to various transition metal oxides and mixed metal oxides [4-9] for this goal, due to the price and limited availability of previous metals. Among these metal oxides, cobaltic oxide $\left(\mathrm{Co}_{3} \mathrm{O}_{4}\right)$ has been explored as a possible substitute for precious metals for $\mathrm{CO}$ oxidation [6-9]. The high activity of $\mathrm{Co}_{3} \mathrm{O}_{4}$ is likely to be due to the relatively low $\Delta \mathrm{H}$ of vaporization of $\mathrm{O}_{2}[10]$. This means that the $\mathrm{Co}-\mathrm{O}$ bond strength of $\mathrm{Co}_{3} \mathrm{O}_{4}$ is relatively weak, leading to the desorption of more lattice oxygen. Thus, many researchers have measured the catalytic activity of $\mathrm{Co}_{3} \mathrm{O}_{4}$ for $\mathrm{CO}$ oxidation [6-9,11].

It is known that the activity and selectivity of a large variety of catalysts can be modified by various methods such as loading on a support [12], doping with certain foreign oxides $[13,14]$, or changing the particle size and surface area. The aim of the present work is to investigate the effect of surface area of $\mathrm{Co}_{3} \mathrm{O}_{4}$ on the change in the $\mathrm{CO}$ oxidation catalytic activity. The techniques employed are X-ray diffraction, nitrogen adsorption at

\footnotetext{
* To whom correspondence should be addressed.

E-mails: chiensh@gate.sinica.edu.tw; chenbin@ccit.edu.tw
}

$-196{ }^{\circ} \mathrm{C}$, infrared spectra, temperature-programmed reduction (TPR) and oxidation of $\mathrm{CO}$ by $\mathrm{O}_{2}$ over different methods (precipitation-oxidation, impregnation, hydrothermal, etc.) prepared $\mathrm{Co}_{3} \mathrm{O}_{4}$ samples.

\section{Experimental}

\subsection{Catalyst preparation}

The high-valence cobalt oxide (marked as $\mathrm{CoO}_{x}$ ) was synthesized by the precipitation-oxidation method in an aqueous solution. The detailed preparation procedure was described in a previous paper [8]. Furthermore, both pure cobaltic oxide $\left(\mathrm{Co}_{3} \mathrm{O}_{4}\right)$ species were refined from $\mathrm{CoO}_{x}$ by a controlled hydrogen reduction in a TPR system to $230{ }^{\circ} \mathrm{C}$ (assigned as PO-R230) and a calcination under $400^{\circ} \mathrm{C}$ for $4 \mathrm{~h}$ in flowing air (assigned as POC400), respectively. The third cobaltic oxide loading 2 wt $\% \mathrm{Na}$ was prepared by the impregnation method. The PO-C400 sample was impregnated with an aqueous solution of $\mathrm{NaNO}_{2}$ (Merck). After stirring for $1 \mathrm{~h}$, the excess water was slowly evaporated at $80^{\circ} \mathrm{C}$, then, further dried at $110^{\circ} \mathrm{C}$ until a constant weight was attained. The obtained sample was calcined at $550{ }^{\circ} \mathrm{C}$ for $4 \mathrm{~h}$ in flowing air (assigned as I-C550). The fourth cobaltic oxide was prepared by the hydrothermal method. This was done by taking $2 \mathrm{~g}$ of commercial cobaltic oxide (Strem, the standard reagent assigned as D-Strem to compare with the four prepared cobaltic oxides) dispersed in $10 \mathrm{M}, 40 \mathrm{~mL}$ aqueous solution of $\mathrm{NaOH}$ with electromagnetic stirring. Then the 
suspension was moved into a Teflon-lined stainless steel autoclave. The sealed autoclave was heated to $150{ }^{\circ} \mathrm{C}$ for $48 \mathrm{~h}$, then cooled to room temperature. The precipitation was filtered and washed with diluted $\mathrm{HCl}$ and deionized water several times, and dried at $110{ }^{\circ} \mathrm{C}$ (assigned as $\mathrm{H}-150$ ).

\subsection{Catalyst characterization}

$\mathrm{X}$-ray diffraction (XRD) measurements were performed using Siemens D5000 diffractometer with $\mathrm{Cu}$ $\mathrm{K}_{\alpha 1}$ radiation $(\lambda=1.5405 \AA)$ at $40 \mathrm{kV}$ and $30 \mathrm{~mA}$ with a scanning speed in $2 \theta$ of $2^{\circ} \mathrm{min}^{-1}$. The crystallite sizes of cobaltic oxide were estimated using the Scherrer equation.

Nitrogen adsorption isotherms at $-196{ }^{\circ} \mathrm{C}$ were determined volumetrically with Micrometritics ASAP 2010. The catalysts were pre-outgassed at $5 \times 10^{-5}$ Torr for $3 \mathrm{~h}$ at $110{ }^{\circ} \mathrm{C}$. The surface area was determined from the nitrogen adsorption isotherm.

The infrared spectra were obtained by a Bomen DA- 8 spectrometer in the range of $500-800 \mathrm{~cm}^{-1}$. One milligram of each powder sample was diluted with $200 \mathrm{mg}$ of vacuum-dried IR-grade $\mathrm{KBr}$ and subjected to a pressure of 8 tons.

Reduction behavior of cobaltic oxide was studied by TPR. About $50 \mathrm{mg}$ of the sample was heated in a flow of $10 \% \mathrm{H}_{2} / \mathrm{He}$ gas mixture at a flow rate of $10 \mathrm{~mL} \mathrm{~min}^{-1}$. During TPR, temperature was increased with $10{ }^{\circ} \mathrm{C} \mathrm{min}^{-1}$ to $700{ }^{\circ} \mathrm{C}$.

\subsection{Catalytic activity measurement}

The catalytic activity of the cobaltic oxide towards $\mathrm{CO}$ oxidation was carried out in a continuous flow micro-reactor. The reaction gas, mixed of $10 \% \mathrm{O}_{2} / \mathrm{He}$ with $4 \% \mathrm{CO} / \mathrm{He}$, was fed to a $0.5 \mathrm{~g}$ catalyst at a rate of $20 \mathrm{~mL} \mathrm{~min}{ }^{-1}$. Steady-state catalytic activity was measured at each temperature with the reaction temperature raised from room temperature to $300^{\circ} \mathrm{C}$ in steps of $25^{\circ} \mathrm{C}$. The effluent gas was analyzed on-line using a Varian 3700 gas chromatograph with a carbosphere column. Before reaction, the catalyst was pretreated in flowing $10 \% \mathrm{O}_{2} / \mathrm{He}$ at $110{ }^{\circ} \mathrm{C}$ for $1 \mathrm{~h}$ to drive away molecules pre-adsorbed from the atmosphere.

\section{Results and discussion}

\subsection{Characteristic analysis}

The diffraction patterns of commercial cobaltic oxide (D-Strem) and the prepared samples are shown in figure 1. The obtained diffraction peaks show that these prepared samples consist mainly of a well-crystallized $\mathrm{Co}_{3} \mathrm{O}_{4}$ phase with a spinel structure. Additional characteristic peak of $\beta-\mathrm{Na}_{0.6} \mathrm{CoO}_{2}$ phase [figure 1(c)] is observed for the I-C550 sample, indicating that $\mathrm{Na}^{+}$ ions diffuse into the bulk of the $\mathrm{Co}_{3} \mathrm{O}_{4}$, resulting in the

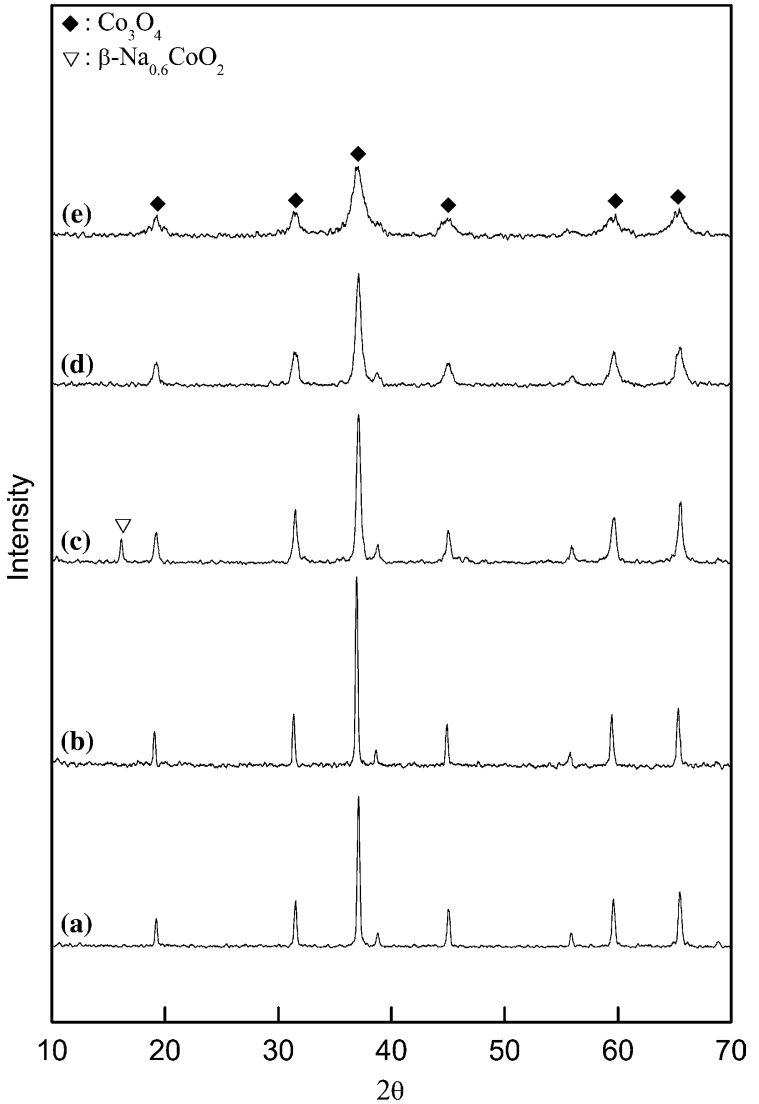

Figure 1. XRD characterization for commercial and the prepared cobaltic oxide: (a) D-Strem (b) H-150 (c) I-C550 (d) PO-C400 (e) POR230.

formation of the composite oxide. In observing the width of the peaks, the considerable broadening of the diffraction peaks can demonstrate the nanocrystalline character of the $\mathrm{Co}_{3} \mathrm{O}_{4}$ phase. It is seen that both D-Strem and H-150 diffraction peaks [figure 1(a and b)] are narrow and sharper than others, indicating a larger crystal size of $\mathrm{Co}_{3} \mathrm{O}_{4}$. When comparing with the POR230 sample [figure 1(e)], the apparent broadening of the diffraction patterns is observed, indicating that the $\mathrm{Co}_{3} \mathrm{O}_{4}$ particle size of PO-R230 is smaller than others. Both PO-C400 and I-C550 samples [figure 1(d and c)] are position medium. According to the (311) diffraction pattern of $\mathrm{Co}_{3} \mathrm{O}_{4}$ crystalline, the particle size can be calculated using the Scherrer equation [15]. The calculated average crystallite sizes are summarized in the sixth column of table 1 . Inspection of these results reveals that: (i). The particle size of $\mathrm{Co}_{3} \mathrm{O}_{4}$ crystalline depends on the prepared methods (ii). The higher the refined temperature, the sharper the diffraction peaks, indicating its crystal size is progressive growth with temperature. The order of particles size is: $\mathrm{H}-150(32.7 \mathrm{~nm})$ $\sim$ D-STREM $(31.8 \mathrm{~nm})>$ I-C550 $(18.8 \mathrm{~nm})>$ POC400 $(15.4 \mathrm{~nm})>$ PO-R230 $(8.2 \mathrm{~nm})$.

The surface area $\left(S_{\mathrm{BET}}, \mathrm{m}^{2} \mathrm{~g}^{-1}\right)$ of commercial and the prepared cobaltic oxide is determined from nitrogen 
Table 1

Variation of $T_{\text {red }}$ of oxide species, surface area and particle size of $\mathrm{Co}_{3} \mathrm{O}_{4}$ with $T_{50}$ on $\mathrm{CO}$ oxidation

\begin{tabular}{|c|c|c|c|c|c|c|}
\hline \multirow[t]{2}{*}{ Sample } & \multicolumn{3}{|c|}{$T_{\text {red }}$ of oxidation spacies $/{ }^{\circ} \mathrm{C}^{*}$} & \multirow[t]{2}{*}{$S_{\mathrm{BET}}\left(\mathrm{m}^{2} \mathrm{~g}^{-1}\right)$} & \multirow[t]{2}{*}{ Particle size $(\mathrm{nm})^{* *}$} & \multirow[t]{2}{*}{$T_{50}\left({ }^{\circ} \mathrm{C}\right)^{* * *}$} \\
\hline & $\mathrm{Co}_{3} \mathrm{O}_{4}$ & $\beta-\mathrm{Na}_{0.6} \mathrm{CoO}_{2}$ & $\mathrm{CoO}$ & & & \\
\hline PO-R230 & 270 & - & 420 & 102 & 8.2 & 98 \\
\hline PO-C400 & 310 & - & 420 & 50.7 & 15.4 & 140 \\
\hline I-C550 & 330 & 290 & 440 & 22.8 & 18.8 & 210 \\
\hline D-Strem & 410 & - & 520 & 1.6 & 31.8 & 220 \\
\hline H-150 & 440 & - & 570 & 1.9 & 32.7 & 225 \\
\hline
\end{tabular}

*: Measured for TPR **: Calculated the Scherrer equation according to the (311) diffraction peak of $\mathrm{Co}_{3} \mathrm{O}_{4} ; * * *$ : Temperature for $50 \% \mathrm{CO}$ conversion.

adsorption isotherms measured at $-196^{\circ} \mathrm{C}$. The data of $S_{\mathrm{BET}}$ are given in the fifth column of table 1 . It is seen that the $S_{\mathrm{BET}}$ increases with decreasing particle size as the following tendency: PO-R230 > PO-C400 > IC550 $>$ H-150 $\sim$ D-Strem. Comparison of PO-R230 (reduction at $230{ }^{\circ} \mathrm{C}$ ) with PO-C400 (calcined at $400{ }^{\circ} \mathrm{C}$ ), the increase in refined temperature induces a decrease in its surface area. The induced decrease due to the thermal treatment might be attributed to grain growth of the particles of cobaltic oxide [12]. In fact, XRD investigations reveals that the rising in refined temperature of different samples from 230 to $550{ }^{\circ} \mathrm{C}$ affects an increase in degree of crystallinity and particle size of $\mathrm{Co}_{3} \mathrm{O}_{4}$ phase.

Figure 2 shows the IR absorption spectra of commercial and the prepared cobaltic oxide. The IR spectra of $\mathrm{Co}_{3} \mathrm{O}_{4}$ display two distinct bands at 562-569 $\left(v_{1}\right)$ and 659-662 $\left(\mathrm{v}_{2}\right) \mathrm{cm}^{-1}$ that originated by the stretching vibrations of the metal-oxygen bond [16,17]. The $v_{1}$ band is characteristic of $\mathrm{OB}_{3}$ (where $\mathrm{B}$ denotes the $\mathrm{Co}^{3+}$ in octahedral hole) vibration and the $v_{2}$ band is attributed to the $\mathrm{ABO}_{3}$ (where $\mathrm{A}$ denotes the $\mathrm{Co}^{2+}$ in tetrahedral hole) vibration in the spinel lattice $[18,19]$. This reveals that the two bands tend to broaden [from figure $2(\mathrm{a}-\mathrm{e})$ ] with a decrease of particle sizes of cobaltic oxide, which could be attributed to the surface effect of nanoparticles. The difference between surface atoms and bulk atoms results in a broadening of absorption peak. At the same time, with decreasing particle size [i.e., POR230 shown in figure 2(e)], the two bands slight shift to a lower wavenumber due to a larger number of defects at the surface of smaller nanoparticle (higher surface area) crystals to weaken the $\mathrm{Co}-\mathrm{O}$ bond strength. The redistribution of free electrons between the surface and the bulk cause a decrease of the bond force constant, and consequently absorption red shifts.

In order to understand the relationship of a $\mathrm{Co}-\mathrm{O}$ bond strength with a surface area (or particle size), further recognized with TPR technique to understand the reduction behavior of $\mathrm{Co}_{3} \mathrm{O}_{4}$ is needed. Figure 3 shows the TPR profiles for commercial and the prepared cobaltic oxide. All the samples except I-C550 and H-150 show a similar TPR profile, consisting of two well- resolved reduction peaks (assigned as $\alpha$ peak and $\beta$ peak). These profiles point to a two-step reduction process: the first one ( $\alpha$ peak) of low intensity, starts at low temperature and overlaps with the more intense second one ( $\beta$ peak). The different shape of the TPR profiles obtained for I-C550 and H-150 is probably due to the presence of composite oxides (XRD measurement reveals the formation of a $\beta-\mathrm{Na}_{0.6} \mathrm{CoO}_{2}$ phase [figure 1(c)] for I-C550 that reduced at $290{ }^{\circ} \mathrm{C}$ [figure 3(c)] )

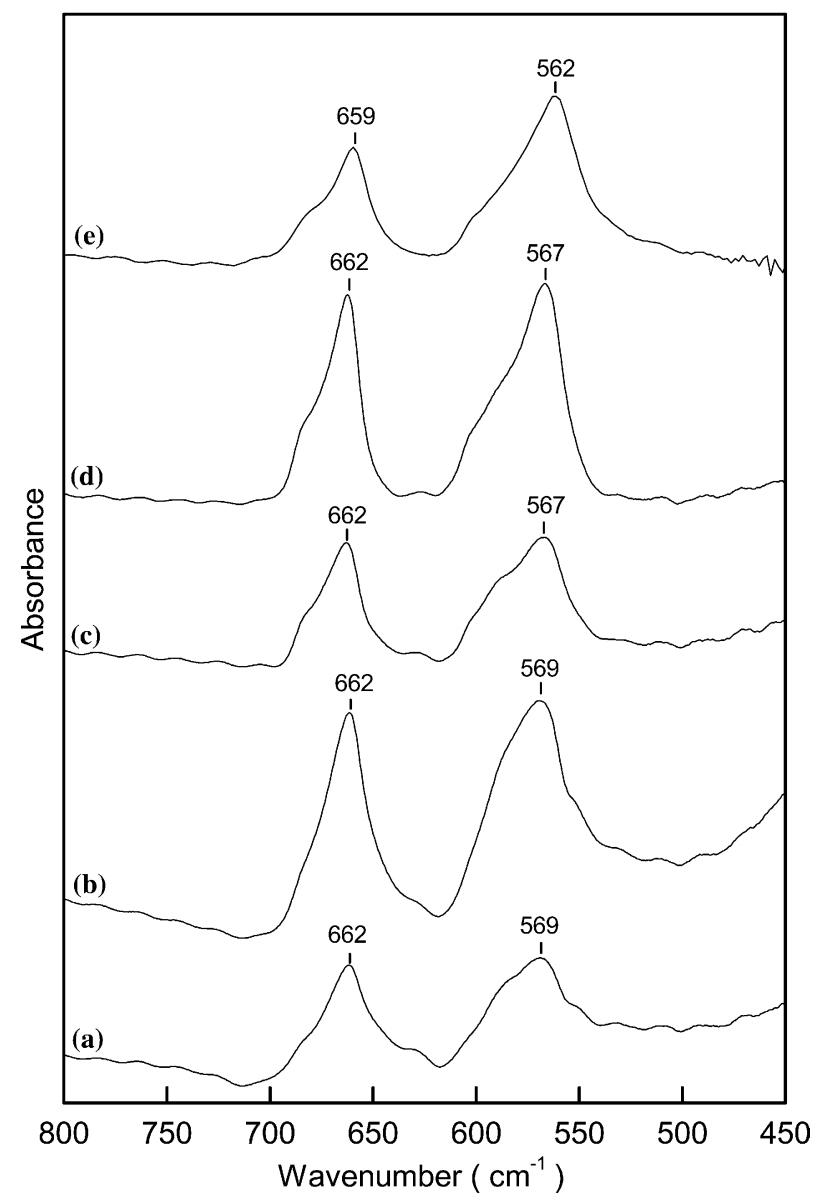

Figure 2. IR characterization for commercial and the prepared cobaltic oxide: (a) D-Strem (b) H-150 (c) I-C550 (d) PO-C400 (e) PO-R230. 


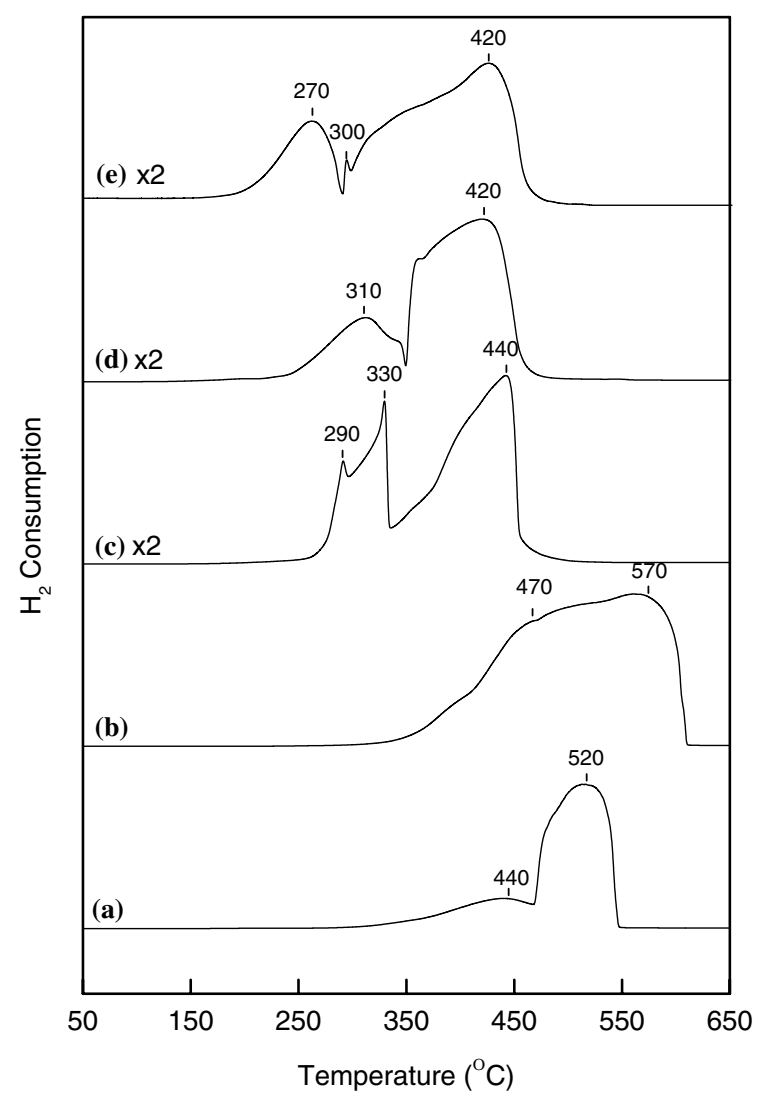

Figure 3. TPR profiles for commercial and the prepared cobaltic oxide: (a) D-Strem (b) H-150 (c) I-C550 (d) PO-C400 (e) PO-R230.

or more sodium which covers the surface of cobaltic oxide (for $\mathrm{H}-150$, no composite oxides formed under XRD measurement [figure 1(b)]) that affect the shape of the reduction profiles. According to the literature [20,21], the low-temperature $\alpha$ peak can be ascribed to the reduction of $\mathrm{Co}^{3+}$ ions, present in the spinel structure, into $\mathrm{Co}^{2+}$ [equation (1)], with the subsequent structural change to $\mathrm{CoO}$, which followed the highertemperature $\beta$ peak and is due to the reduction of $\mathrm{CoO}$ to metallic cobalt [equation (2)].

$$
\begin{gathered}
\mathrm{Co}_{3} \mathrm{O}_{4}+\mathrm{H}_{2} \rightarrow 3 \mathrm{CoO}+\mathrm{H}_{2} \mathrm{O} \\
\mathrm{CoO}+\mathrm{H}_{2} \rightarrow \mathrm{Co}+\mathrm{H}_{2} \mathrm{O}
\end{gathered}
$$

As can be seen in figure 3 and the 2 nd and 4 th columns of table 1 , both the $\alpha$ peak and $\beta$ peak appear shifted to higher temperatures as the surface area of cobaltic oxide decreases, i.e., the $\alpha$ peak and $\beta$ peak of PO-R230 sample $\left(S_{\mathrm{BET}}=102 \mathrm{~m}^{2} \mathrm{~g}^{-1}\right)$ is 270 and $420{ }^{\circ} \mathrm{C}$ [figure 3(e)], respectively. While, the $\alpha$ peak and $\beta$ peak of I-C550 sample $\left(S_{\mathrm{BET}}=22.8 \mathrm{~m}^{2} \mathrm{~g}^{-1}\right)$ is 330 and $440{ }^{\circ} \mathrm{C}$ [figure 3(c)], respectively. The shift in the reduction profile of $\mathrm{Co}_{3} \mathrm{O}_{4}$ toward higher temperature is marked more as the $S_{\mathrm{BET}}$ decreases to one order, i.e., the $\alpha$ peak and $\beta$ peak shift to 410 and $520{ }^{\circ} \mathrm{C}$ [figure 3(a)], respectively, for D-Strem sample $\left(S_{\mathrm{BET}}=1.6 \mathrm{~m}^{2} \mathrm{~g}^{-1}\right.$. These results indicate that the optimum $S_{\mathrm{BET}}$ of $\mathrm{Co}_{3} \mathrm{O}_{4}$ can weaken the bond strength of $\mathrm{Co}-\mathrm{O}$ and promote more lattice oxygen desorption from $\mathrm{Co}_{3} \mathrm{O}_{4}$ to decrease the reduction temperature.

\subsection{Catalytic activity}

Catalytic carbon monoxide oxidation has drawn great attention in recent years because carbon monoxide is a well-known pollutant from automobile exhaust. Therefore, it is interesting to study the catalytic properties on the effect of surface area of $\mathrm{Co}_{3} \mathrm{O}_{4}$ to determine whether the strength of the $\mathrm{Co}-\mathrm{O}$ bonds weaken with the increasing of the $S_{\mathrm{BET}}$ and if it can promote the activity towards carbon monoxide oxidation. The steady-state catalytic activities for carbon monoxide oxidation on commercial and the prepared cobaltic oxide are compared and given at increasing temperatures in figure 4. The $\mathrm{CO}$ conversion over each sample generally increased with the reaction temperature. The observed $T_{50}$ (the conversion of $\mathrm{CO}$ reached 50\%) is chosen to judge the catalytic activity for each sample shown in the last column of table 1. Clearly, the activity of $\mathrm{Co}_{3} \mathrm{O}_{4}$ toward $\mathrm{CO}$ oxidation is enhanced significantly by increasing the $S_{\mathrm{BET}}$. Compared to the $S_{\mathrm{BET}}$ (the fifth

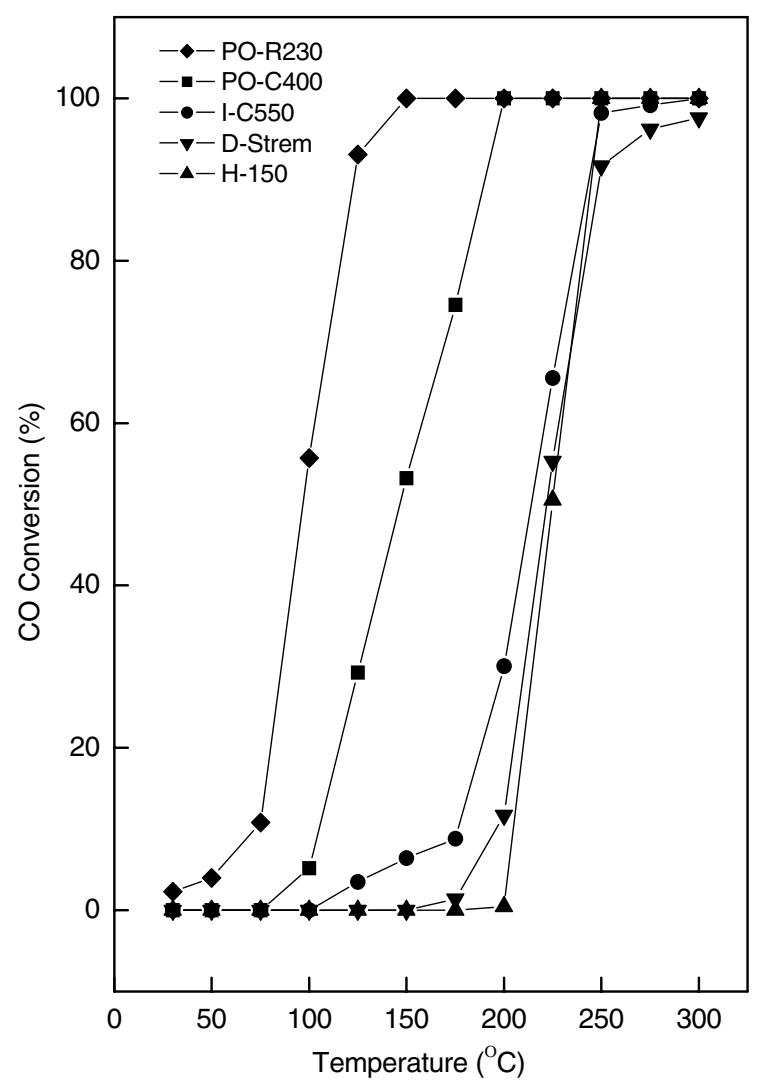

Figure 4. Conversion profiles for $\mathrm{CO}$ oxidation over commercial and the prepared cobaltic oxide: $(\bullet)$. PO-R230 (ם). PO-C400 (๑). I-C550

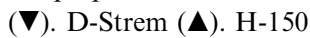


column of table 1) of $\mathrm{Co}_{3} \mathrm{O}_{4}$, the $T_{50}$ decreased significantly by increasing the $S_{\mathrm{BET}}$, i.e., PO-R $230\left(T_{50}=98^{\circ} \mathrm{C}\right.$ and $\left.S_{\mathrm{BET}}=102 \mathrm{~m}^{2} \mathrm{~g}^{-1}\right)>\mathrm{PO}-\mathrm{C} 400 \quad\left(T_{50}=140{ }^{\circ} \mathrm{C}\right.$ and $\left.S_{\mathrm{BET}}=50.7 \mathrm{~m}^{2} \mathrm{~g}^{-1}\right)>\mathrm{I}-\mathrm{C} 550\left(T_{50}=210{ }^{\circ} \mathrm{C}\right.$ and $\left.S_{\mathrm{BET}}=22.8 \mathrm{~m}^{2} \mathrm{~g}^{-1}\right)>\mathrm{H}-150\left(T_{50}=225^{\circ} \mathrm{C}\right.$ and $S_{\mathrm{BET}}=$ $\left.1.9 \mathrm{~m}^{2} \mathrm{~g}^{-1}\right) \sim \mathrm{D}$-Strem $\left(T_{50}=220^{\circ} \mathrm{C}\right.$ and $S_{\mathrm{BET}}=$ $1.6 \mathrm{~m}^{2} \mathrm{~g}^{-1}$. The best active sample (PO-R230) is achieved over the low-temperature refined (reduction under TPR system to $230{ }^{\circ} \mathrm{C}$ ), where $T_{50}$ is reached at temperatures as low as $100{ }^{\circ} \mathrm{C}$ and full conversion is reached at about $150{ }^{\circ} \mathrm{C}$. While the $T_{50}$ for the least active sample (H-150) reaches around $225^{\circ} \mathrm{C}$ and full conversion is reached at the temperature above $300{ }^{\circ} \mathrm{C}$.

The catalyst via the low temperature refined for the PO-R230 may produce some specific sites of defects which increase the $S_{\mathrm{BET}}$ to adsorb gas molecules and weaken the $\mathrm{Co}-\mathrm{O}$ bond strength that promotes the $\mathrm{CO}$ oxidation activity. The increase in $T_{50}$ for the $\mathrm{H}-150$ maybe that sodium covered on the surface of cobaltic oxide decreases the $S_{\mathrm{BET}}$ to affect the tendency to adsorb gas molecules and enhance the $\mathrm{Co}-\mathrm{O}$ bond strength to depress the $\mathrm{CO}$ oxidation activity. According to the above characterization results, the temperatures for $50 \%$ oxidation of carbon monoxide are gradually lowered by increasing the $S_{\mathrm{BET}}$ of $\mathrm{Co}_{3} \mathrm{O}_{4}$ mainly due to a weakening in the strength of the $\mathrm{Co}-\mathrm{O}$ bonds and the acceleration of oxygen desorption from $\mathrm{Co}_{3} \mathrm{O}_{4}$. Figure 5 displays that the obtained $T_{50}$ can be correlated with the stoichiometry as

$$
T_{50}\left({ }^{\circ} \mathrm{C}\right)=-1.4 S_{\mathrm{BET}}+227
$$

The $T_{50}$ increases about $100{ }^{\circ} \mathrm{C}$ as the $S_{\mathrm{BET}}$ decreases from $100 \mathrm{~m}^{2} \mathrm{~g}^{-1}$ to $2.0 \mathrm{~m}^{2} \mathrm{~g}^{-1}$.

\section{Conclusion}

A series of cobaltic oxide samples prepared by different preparation methods are investigated. The cor-

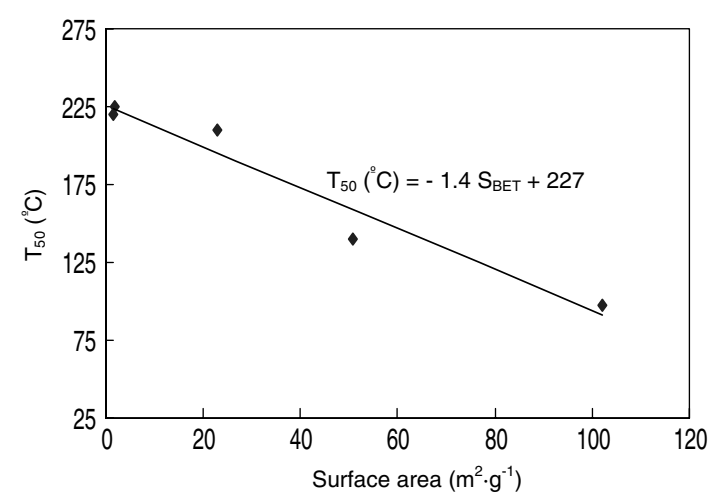

Figure 5. Correlation of surface area of cobaltic oxide with the $T_{50}$ on $\mathrm{CO}$ oxidation. relations between catalytic activity and $S_{\mathrm{BET}}$ properties are obtained and show as follows:

(1) The particle size of $\mathrm{Co}_{3} \mathrm{O}_{4}$ crystalline depends on the prepared methods and refined temperature. The order of particle size is: $\mathrm{H}-150 \quad(32.7 \mathrm{~nm})$ $\sim$ D-STREM $(31.8 \mathrm{~nm})>$ I-C550 $(18.8 \mathrm{~nm})>$ POC400 $(15.4 \mathrm{~nm})>$ PO-R230 $(8.2 \mathrm{~nm})$.

(2) The order of $S_{\mathrm{BET}}$ is:PO-R230 $\left(102 \mathrm{~m}^{2} \mathrm{~g}^{-1}\right)>$; PO-C400 (50.7 $\left.\mathrm{m}^{2} \mathrm{~g}^{-1}\right)>$ I-C550 $\left(22.8 \mathrm{~m}^{2} \mathrm{~g}^{-1}\right)>$ H-150 $\left(1.9 \mathrm{~m}^{2} \mathrm{~g}^{-1}\right) \sim \mathrm{D}-\operatorname{Strem}\left(1.6 \mathrm{~m}^{2} \mathrm{~g}^{-1}\right)$.

(3) The $T_{50}$ is decreased significantly by increasing the $S_{\text {BET }}$,i.e.,PO-R230 $\left(98^{\circ} \mathrm{C}\right)>$ PO-C $400\left(140{ }^{\circ} \mathrm{C}\right)>$ $\mathrm{I}-\mathrm{C} 550 \quad\left(210^{\circ} \mathrm{C}\right)>\mathrm{H}-150 \quad\left(225^{\circ} \mathrm{C}\right) \quad \sim$ D-Strem $\left(220^{\circ} \mathrm{C}\right)$.

\section{Acknowledgments}

We are pleased to acknowledge the financial support for this study by the National Science Council of the Republic of China under contract number NSC 922113-M-014-001.

\section{References}

[1] Y. Kim, S.K. Shi and J.H. White, J. Catal. 61 (1980) 61.

[2] Y.Y. Yao, J. Catal. 89 (1984) 152.

[3] M. Olsbye, R. Wendelbo and T. Akporiayc, Appl. Catal. A 152 (1997) 127.

[4] F. Severino and J. Laine, Ind. Eng. Chem. Prod. Res. Dev. 22 (1983) 396.

[5] W. Liu and F.S. Maria, J. Catal. 153 (1995) 304.

[6] J. Jansson, J. Catal. 194 (2000) 55.

[7] J. Jansson, A.E.C. Palmqvist, E. Fridell, M. Skoglundh, L.O. Sterlund, P. Thormahlen and V. Langer, J. Catal. 211 (2002) 387.

[8] H.K. Lin, C.B. Wang, H.C. Chiu and S.H. Chien, Catal. Lett. 86 (2003) 63.

[9] H.K. Lin, H.C. Chiu, H.C. Tsai, S.H. Chien and C.B. Wang, Catal. Lett. 88 (2003) 169.

[10] B.A. Sazonov, V.V. Popovskii and G.K. Boreskov, Kinet. Catal. 9 (1968) 255.

[11] D.S. Lafyatis, G.P. Ansell, S.C. Bennett, J.C. Frost, P.J. Millington, R.R. Rajaram, A.P. Walker and T.H. Ballinger Applied Catal.., B 18 (1998) 123.

[12] G.A. El-Shobaky and N.M. Deraz, Mater. Lett. 47 (2001) 231.

[13] N.M. Deraz, Colloids Surf. A 207 (2002) 197.

[14] G.A. El-Shobaky and A.M. Ghozza, Mater. Lett. 58 (2004) 699.

[15] H.P. Klug and L.E. Alexander, X-ray Diffraction Procedures for Polycrystalline and Amorphous Materials (Wiley, New York, 1962) 491.

[16] C. Spenser and D. Schroeder, Phys. Rev. B 9 (1974) 3658.

[17] T. Andrushkevich, G. Boreskov, V. Popovskii, L. Pliasova, L. Karakchiev and A. Ostankovitch, Kinet. Katal. 6 (1968) 1244.

[18] G. Christoskova St., M. Stoyanova, M. Georgieva and D. Mehandjiev, Mater. Chem. and Phys. 60 (1999) 39.

[19] R.N. Singh, J.P. Pandey, N.K. Singh, B. Lal, P. Chartier and J.F. Koenig, Electrochim. Acta 45 (2000) 1911.

[20] P. Arnoldy and J.A. Moulijn, J. Catal. 93 (1985) 38.

[21] M. Vo $\beta$, D. Borgmann and G. Wedler, J. Catal. 212 (2002) 10. 